\title{
Preface for Vol 8 FOSS4G Prague
}

This special issue about the FOSS4G-CEE \& Geoinformatics 2012, held for the first time in May 2012, is offering selected reviewed papers of the conference. Geoinformatics FCE CTU, started in 2006 at the Department of Mapping and Cartography, Faculty of Civil Engineering, Czech Technical University in Prague, covered the academic section of FOSS4G-CEE.

The acronym FOSS4G was first introduced in 2004 as an acronym for Free and Open Source Software for Geoinformatics by a Japanese research group in a publication and then used for the GRASS GIS Users Conference held in 2004 in Bangkok, Thailand. Later on this acronym was transferred to Open Source Geospatial Foundation (OSGeo.org) for their annual conference. The FOSS4G-CEE 2012 was the first regional FOSS4G conference in Central and East Europe.

There were more than sixty presentations, six workshops and five tutorials accepted for the conference. Number of registered participants was 120 from twenty countries, namely the Czech Republik (35), Romania (14), Germany (12), France (6), Austria (5), Slovakia (4) and Estonia, Hungary, Switzerland, Poland, Turkey, USA, Italy, United Kingdom, Croatia, Rwanda, New Zealand, Georgia, Ghana and Nigeria (ranging from 3 to 1 participants).

\section{Plenary speakers}

Arnulf Christl (OSGeo) works as Systems Architect in the spatial do-

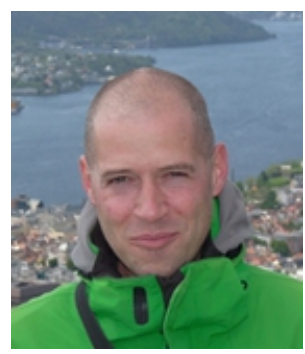
main since the late nineties. His core competencies are distributed spatial data infrastructures, metadata, agile development and Free and Open Source Software methodology, deployment and business models. He is president of the Open Source Geospatial Foundation (OSGeo) which he co-founded in 2006. He is member of the Open Geospatial Consortium (OGC) Architecture Board coordinating international standard development. He contributes to the European INSPIRE process through his company metaspatial providing consultancy for international SDI projects. In his latest project he worked as Technical Coordinator of the eContent+ funded project ESDIN and contributed to the European Location Framework architecture (1.5MB PDF). ESDIN is a consortium of 20 European National Mapping and Cadastre Agencies, private industry and academia headed by EuroGeographics. 


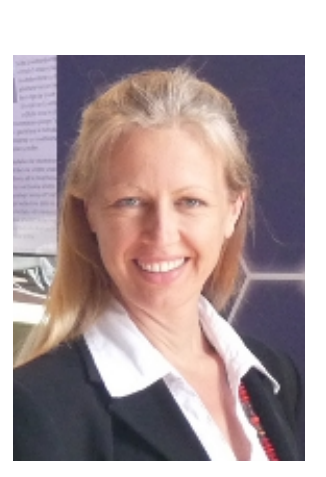

Athina Trakas is OGC's Director for European Services. In her position she is the contact person for OGC in Europe, responsible for the OGC's activities and networking in Europe. This includes connecting with European stakeholder organisations, the European Commission and members, supporting regional and national forum activities and planning and managing of OGC outreach and recruitment. She has a diploma in Geography and started working in the field of GIS in 1998. Until 2006 she was responsible for marketing and key account management at CCGIS, a consultancy company for GIS. In 2006 she joined OGC as Director for Business Development on a part time basis. From 2007 to 2008 Athina was also responsible for Business Development, Marketing and International Business at WhereGroup for Free and Open Source GIS and standards. Since 2008 she is charter member of the Open Source Geospatial Foundation (OSGeo). In 2009 she was appointed OGC's Director for European Services.

Helena Mitasova (OSGeo) is Associate Professor at the Department

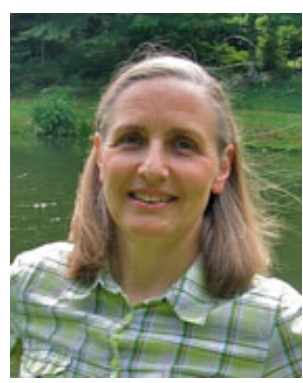
of Marine, Earth and Atmospheric Sciences, and a member of the Geospatial Science and Technology Faculty at North Carolina State University (NCSU) in Raleigh, NC, USA. She has been a member of the open source GRASS GIS development team since 1991 and she co-authored the first book on GRASS, now in its third edition. She is a member of editorial board for Transactions in GIS and a charter member of Open Source Geospatial Foundation. Her research at the University of Illinois, US Army Construction Engineering Research Laboratories in Champaign and currently at NCSU has focused on methods for terrain analysis, geospatial modeling and visualization. Her PhD is from the Slovak Technical University, Bratislava, Slovakia.

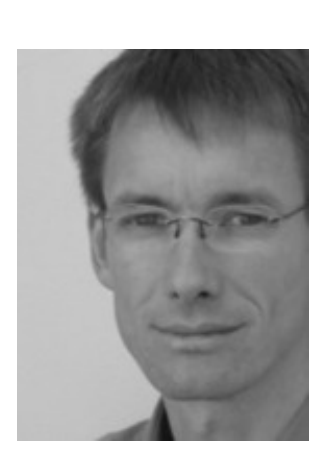

Markus Neteler (OSGeo) is head of the GIS and Remote Sensing unit at the Research and Innovation Centre of the Edmund Mach Foundation, Trento, Italy. His main research interests are remote sensing for environmental risk assessment, epidemiological GIS modelling and Free Software GIS development, the latter since 1993. He is principal GIS analyst in several European and national project related to vector-borne diseases and biodiversity. He is author/co-author of two books on the Open Source Geographical Information System GRASS and various papers on GIS applications. He is founding-member of the Open Source Geospatial Foundation and served in its board of directors from 2006-2011.

Vasile Craciunescu (geo-spatial.org) is a researcher at Romanian Na-

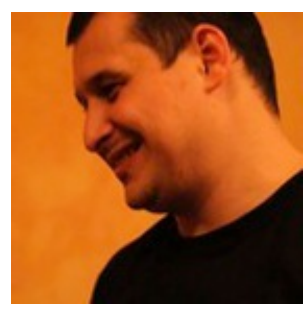
tional Meteorological Administration, working in the Remote Sensing \& GIS Laboratory since 2001. He received his diploma in cartography and physical geography in 2001. Currently is in charge of the scientific and operational activities in Meteo Romania related to rapid mapping, air quality data integration, spatial data infrastructure and web mapping. Vasile is a FOSS4G and open data promoter and use his free time to further develop geo-spatial.org, a collaborative effort by and for the Romanian community to facilitate the sharing of geospatial knowledge and the discovery and publishing of free geographic datasets and maps. 


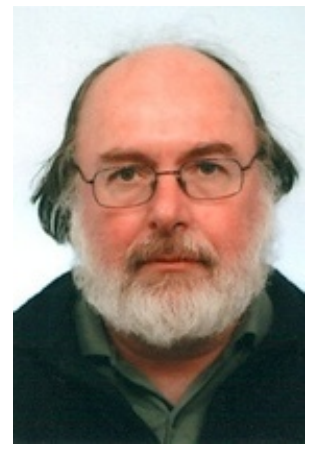

Jiri Polacek (Czech Office for Surveying, Mapping and Cadastre) works as head of the Cadastral Central Database (Section of the Czech Office for Surveying, Mapping and Cadastre) since 2000. In this position is responsible for the operational run of the Information System of Cadastre of Real Estates (ISCRE), customer services and data management linked with ISCRE database. The section is strictly involved in the implementation of the INSPIRE directive for related data themes (as „Cadastral parcels“ etc.). Since 1975 till 2000 he worked in several researcher positions concerned with IT projects, his main research interests are computer graphics a image processing linked with GIS. His PhD is from the Czech Technical University, Prague. He keeps a longterm cooperation with the university as an external teacher and a member of scientific branch committee. He is a member of presidium of the Czech Association for geoinformation (CAGI).

This special issue addresses a series of different topics. In the first paper, Jiří Poláček and Petr Souček report about the procedure of implementation of the INSPIRE directive and Web services for cadastral related themes over the past years for the Czech Cadastre. Related to this, the paper by Anna Kratochvílová and Václav Petráš introduce a new Quantum GIS plugin for Czech cadastral data which supports the new Czech cadastral exchange data format. Two papers are focusing on geospatial software analysis: The paper by Peter Löwe introduces a new module for GRASS GIS which enables the user to perform rule-based analysis and workflow management. The article by Adéla Volfová and Martin Šmejkal gives a short introduction to R, the free software environment for statistical computing and graphics with focus on the geospatial data analysis functionality and methods.

The paper by Ikechukwu Maduako proposes a heterogeneous sensor database framework with geo-processing spatial analysis functionality integrated in the Sensor Observation Services (SOS). In their paper, Miloš Tichý at al. present the current system of discovery of dangerous Near-Earth small bodies which have a chance to collide with the Earth. The article by R. Nétek illustrates how e-learning systems along with Open Source solutions are used at the Palacký University in Olomouc, Czech Republic.

Markus Neteler and Aleš Čepek

Editorial Board

October 2012 